\title{
Forced oscillation technique (FOT): a new tool for epidemiology of occupational lung diseases?
}

\author{
Q.T. Pham*, E. Bourgkard*, N. Chau*, G. Willim*, S.E. Megherbi*, \\ D. Teculescu*, A. Bohadana*, J.P. Bertrand**
}

Forced oscillation technique (FOT): a new tool for epidemiology of occupational lung diseases? Q.T. Pham, E. Bourgkard, N. Chau, G. Willim, S.E. Megherbi, D. Teculescu, A. Bohadana, J.P. Bertrand. (CERS Journals Ltd 1995.

ABSTRACT: The aim of this study was to evaluate the usefulness of the forced oscillation technique (FOT) in the assessment of occupation-related airway changes. The forced oscillation technique and conventional lung function tests were applied in 80 underground coalface workers, aged 35-48 yrs, with chest roentgenogram films classified 0/1 or 1/0 according to the International Labour Office (ILO) classification ( $G$ group), and two control groups matched for age and smoking habits. The first control group, was made up of face-workers having normal chest radiographs, whilst the second comprised underground non-face-workers with normal chest radiographs.

Spirometric, plethysmographic and transfer factor of the lungs for carbon monoxide single-breath $\left(T_{L}, \mathrm{CO}, \mathrm{sb}\right)$ indices revealed no significant differences between the three groups. As regards the forced oscillation technique, a higher value of resistance/frequency slope $\left(\mathrm{Pa} \cdot \mathrm{L}^{-1} \cdot \mathrm{s}^{2}\right)$ was found in the G group compared with the control groups; 2.11 vs 1.06 in the face-workers, and 1.58 in the underground workers. In all three groups, the forced oscillation technique indices (mean resistance $(\bar{R})$, resistance at zero frequency $(R 0)$, resistance/frequency slope $(S)$, and resonant frequency $(f 0)$ ) were found to be higher in subjects having a decreased forced expiratory volume in one second (FEV1) $(\leq 90 \%$ predicted) or a mildly obstructive pattern of ventilatory function, even though this did not reach statistical significance in each of the groups.

These findings together with the feasibility and acceptability of the forced oscillation technique would suggest that it may be a suitable tool for epidemiological studies of occupational respiratory diseases.

Eur Respir J., 1995, 8, 1307-1313.

Lung function tests provide objective evidence of respiratory disability, particularly that due to occupational exposure. Spirometry is the most frequently used technique but requires a high degree of collaboration on the part of the subject. Furthermore, forced inspiratory and expiratory manoeuvres may change bronchial tone and modify airway patency. Currently, body plethysmography is used less often in respiratory epidemiology. It measures intrathoracic gas volume and airway resistance. Again these measurements require a high degree of understanding and co-operation on the part of the subject.

As a result of on-line digital processing [1-5], respiratory impedance measurements by the forced oscillation technique (FOT), have been used increasingly in recent years [6-10]. This technique was first proposed by DuBoIs et al. [11] in 1956, and is based on the relationship between the sinusoidal pressure variations applied to the respiratory system via the mouth [7], by means of an external generator, and the induced flow oscillations. It assesses resistive, elastic and inertial properties of the respiratory system. Data collection takes
*INSERM U 420, Faculté de Médecine, Vandœuvre-lès-Nancy, France. **Houillères du Bassin de Lorraine, Centre de Médecine du Travail, Freyming-Merlebach, France.

Correspondence: Q.T. Pham

INSERM U 420

Faculté de Médecine

B.P. 184

54505 Vandœuvre-lès-Nancy Cedex

France

Keywords: Epidemiological studies forced oscillation technique plethysmography

spirometry

transfer capacity of the lungs for monoxide

Received: May 41994

Accepted after revision March 251995

This work was carried out within the framework of European Coal and Steel Community, Contract No. 7280.03.001, and supported by the "Fondation de France". place over a few respiratory cycles of quiet breathing, enabling serial measurements to be carried out, and requiring minimum co-operation on the part of the subject. Furthermore, the simplicity of the apparatus makes the FOT a potentially useful technique for epidemiological studies.

This study compares FOT and conventional lung function tests (spirometry, plethysmography and CO transfer test) in an epidemiological study on coal workers with or without early signs of pneumoconiosis.

\section{Material and methods}

The sample studied consisted of 80 miners, aged 35-48 yrs, who had worked for more than 10 yrs at face-work and showed radiological signs of possible pneumoconiosis (termed $\mathrm{G}$ group). They were selected from miners satisfying these criteria who had recent chest radiographs that were classified $0 / 1$ or $1 / 0$ according to the International Labour Office (ILO) classification [12], by at least three of four independent trained readers [13]. Two control groups of 80 workers were selected. The first 
control group (CG1) was made up of miners who had also worked for more than 10 yrs at face-work but with normal chest radiographs $(0 / 0)$; whilst the second control group (CG2) comprised underground miners with normal chest radiographs who had worked at face-work for less than 2 yrs. Each subject of each control group was matched with one subject of the $G$ group for age ( \pm 2 yrs) and smoking habits. All the miners involved had given their written consent.

The mean values of dust measured with the CPM3 apparatus at the workface were $1.49-3.79 \mathrm{mg} \cdot \mathrm{m}^{-3}$ for the year 1989, according to the figures supplied by mines of the Houillières du Bassin de Lorraine (H.B.L.), and $0.2-1 \mathrm{mg} \cdot \mathrm{m}^{-3}$ for the other underground sites.

The protocol included: clinical examination; the European Coal and Steel Community (ECSC) questionnaire on pulmonary symptoms and smoking habits; additional questions about job history; respiratory function tests with spirometry, plethysmography, CO single-breath test; and forced oscillations technique (FOT). Chronic bronchitis was defined as cough and expectoration for at least 3 months a year over a period of 2 yrs or more.

\section{Spirometry}

Spirometric measurements were obtained whilst the subjects were in a sitting position by using a computerized spirometer (Spiromatic L. Martin). Flow-volume curves were displayed on a screen, and three valid curves were required (with less than 5\% difference in forced vital capacity (FVC) between the curves). From the envelope curve [14] (a composite curve obtained by superimposing the envelopes of all individual curves from their start points, i.e. at full inspiration), the following parameters were calculated: FVC, forced expiratory volume in one second, (FEV1), maximum mid-expiratory flow (MMEF), peak expiratory flow (PEF), and maximum expiratory flows at 75,50 , and $25 \%$ of vital capacity (FEF75\%, FEF50\%, FEF25\%). Predicted values, proposed by QUANJER [15], were calculated automatically. A mild obstructive pattern of ventilatory function was defined as follows: FVC $\geq$ predicted -SD, and FEV1 and/or MMEF $\leq$ predicted -SD, and normal residual volume (RV) (predicted \pm SD).

\section{Plethysmography}

Plethysmographic measurements were obtained with an isovolume plethysmograph (Master Lab Body Jaeger). When thermal equilibrium had been achieved in the box, the subject was invited to fit the noseclip and breathe through a mouthpiece connected to a pneumotachograph (Fleisch No. 3). Five airway resistance (Raw; $\left.\mathrm{hPa} \cdot \mathrm{L}^{-1} \cdot \mathrm{s}\right)$ measurements were obtained and their mean values were calculated.

\section{Forced oscillation technique}

The measurements were carried out with a Pulmosfor apparatus (SEFAM), shown in schematic form in figure 1.

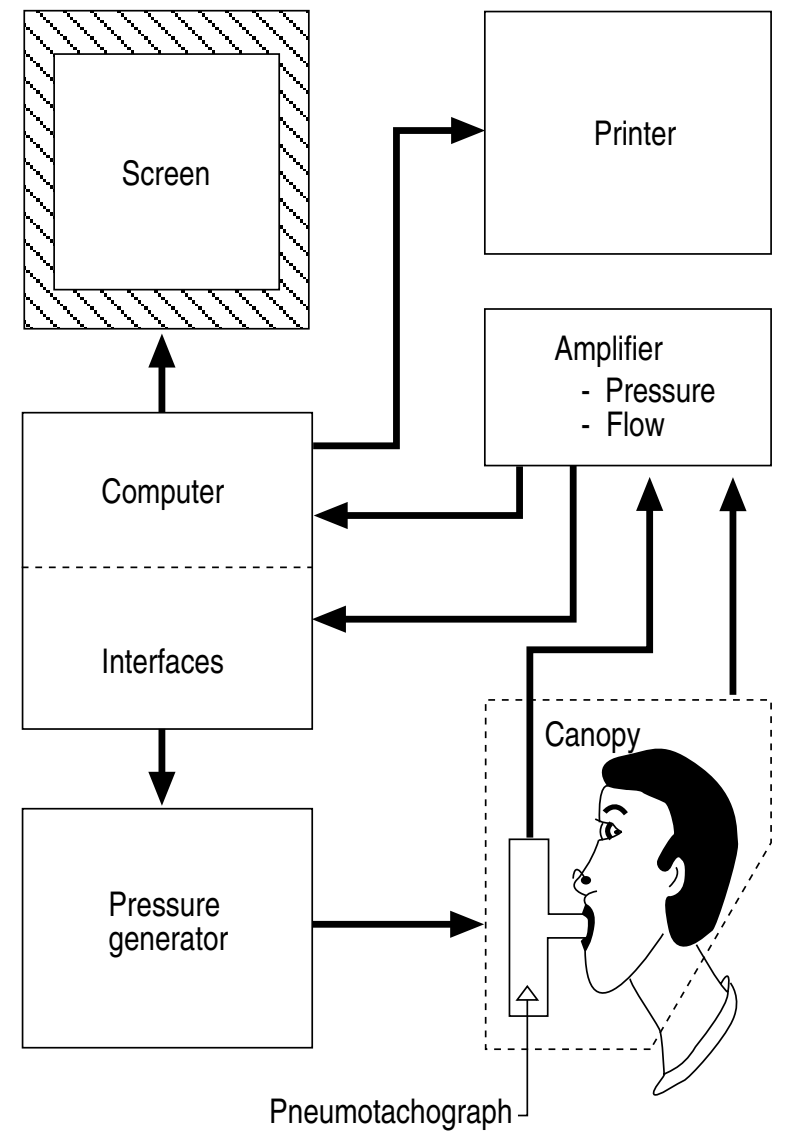

Fig. 1. - Schematic diagram of the apparatus used for the forced oscillation technique (FOT).

The subjects, whilst in a seated position with their head in a canopy and wearing the noseclip, breathed quietly through a Fleisch pneumotachograph. Pressure oscillations at frequencies of $4-32 \mathrm{~Hz}$ were applied to the mouth and in the head canopy by means of a loudspeaker. Spectral analysis of the resulting pressure and flow signals was performed by a computer. It yielded calculations of the mean resistance $\left(\bar{R} ; \mathrm{hPa} \cdot \mathrm{L}^{-1} \cdot \mathrm{s}\right)$ over the entire frequency range, the slope of resistance $v s$ frequency $\left(\mathrm{S} ; \mathrm{Pa} \cdot \mathrm{L}^{-1} \cdot \mathrm{S}^{2}\right)$, and the resistance at the point of origin $\left(R 0 ; \mathrm{hPa} \cdot \mathrm{L}^{-1} \cdot \mathrm{s}\right)$, using the linear regression method $(R(f)=R 0+\mathrm{S} \times f$, where $f$ represents the frequency). The $R 0$ was the resistance extrapolated to zero frequency, and $\mathrm{S}$ defined the variation in resistance with frequency. The values of compliance $\left(C ; \mathrm{mL} \cdot \mathrm{hPa}^{-1}\right)$, inertance $\left(I ; \mathrm{Pa} \cdot \mathrm{L}^{-1} \cdot \mathrm{s}^{2}\right)$, and of resonant frequency $(f 0$; $\mathrm{Hz}$ ), were also calculated [4]. Coherence, a quantitative estimate of the reliability of the FOT determination at each frequency, was calculated and was required to be $\geq 0.95$ to be accepted as a measurement $[16,17]$. Three measurements were made, each lasting $15 \mathrm{~s}$, and the values were averaged.

\section{Carbon monoxide test}

A single-breath carbon monoxide test was performed with the Alveolo test (Jaeger), using a mixture of $\mathrm{CO}$ $3 \%, \mathrm{He} 5 \%$ and air. Two correct measurements were 
Table 1. - Characteristics of the subjects in the 2 control groups (CG1 and CG2) and those with early signs of pneumoconiosis $(\mathrm{G})$

\begin{tabular}{lccc}
\hline & $\mathrm{G}$ & $\mathrm{CG} 1$ & $\mathrm{CG} 2$ \\
\hline $\begin{array}{l}\text { Subjects n } \\
\text { Age yrs* }\end{array}$ & 80 & 80 & 80 \\
$\begin{array}{l}\text { Height cm* } \\
\text { Weight kg* }\end{array}$ & $175(6)$ & $43(3)$ & $42(4)$ \\
$\begin{array}{l}\text { Smoking habit n } \\
\quad \text { Nonsmokers }\end{array}$ & 18 & $174(6)$ & $175(6)$ \\
$\begin{array}{l}\text { 1-19 pack yrs } \\
\geq 20 \text { pack-yrs }\end{array}$ & 40 & $79(12)$ & $78(11)$ \\
$\begin{array}{l}\text { Tobacco consumption } \\
\text { pack-yrs* }\end{array}$ & $11.8(10.4)$ & $11.9(10.7)$ & $14.7(11.6)$ \\
$\begin{array}{l}\text { Total duration of } \\
\text { underground work yrs* }\end{array}$ & $24.4(5.8)$ & $23.4(6.8)$ & $18.2(8.8)$ \\
& & & \\
\end{tabular}

*: data are presented as mean, and SD in parenthesis. For definition of groups see Material and methods section. No significant difference was found among groups except for the total duration of underground work, which was significantly lower in the CG2 group $(\mathrm{p}<0.001)$. G Group: face-workers with pulmonary radiographs classified $0 / 1$ or $1 / 0$ according to the International Labour Office Classification; CG1 group: faceworkers with normal pulmonary radiographs; CG2 group: underground non-face-workers with normal pulmonary radiographs. required with the transfer factor of the lung for carbon monoxide $\left(T \mathrm{~L}, \mathrm{CO} ; \mathrm{mL} \cdot \mathrm{min}^{-1} \cdot \mathrm{mmHg}^{-1}\right)$ and transfer coefficient $\left(T \mathrm{~L}, \mathrm{CO} / V_{\mathrm{A}}\right)$ values being taken as the means of the two.

\section{Statistical methods}

The frequencies of respiratory symptoms and the distributions of smoking habits in the three groups were compared by $\chi^{2}$ test. Age, height, weight, and tobacco consumption were compared by unpaired t-test [18]. Lung function indices were compared by analysis of covariance [19]. The receiver operating characteristic (ROC) curves [19], were calculated by pooling the subjects of the three groups for each FOT index that was significantly different between the subjects with FEV1 $>90 \%$ pred and those with FEV $1 \leq 90 \%$ pred, and between the subjects with and without obstructive pattern of lung function. All of the statistical analyses were made using the SAS [20] programs.

\section{Results}

The three groups were of similar age, height and weight and had similar smoking habits (table 1). Cough,

Table 2. - Pulmonary function tests (spirometry, plethysmography, and forced oscillation technique (FOT))

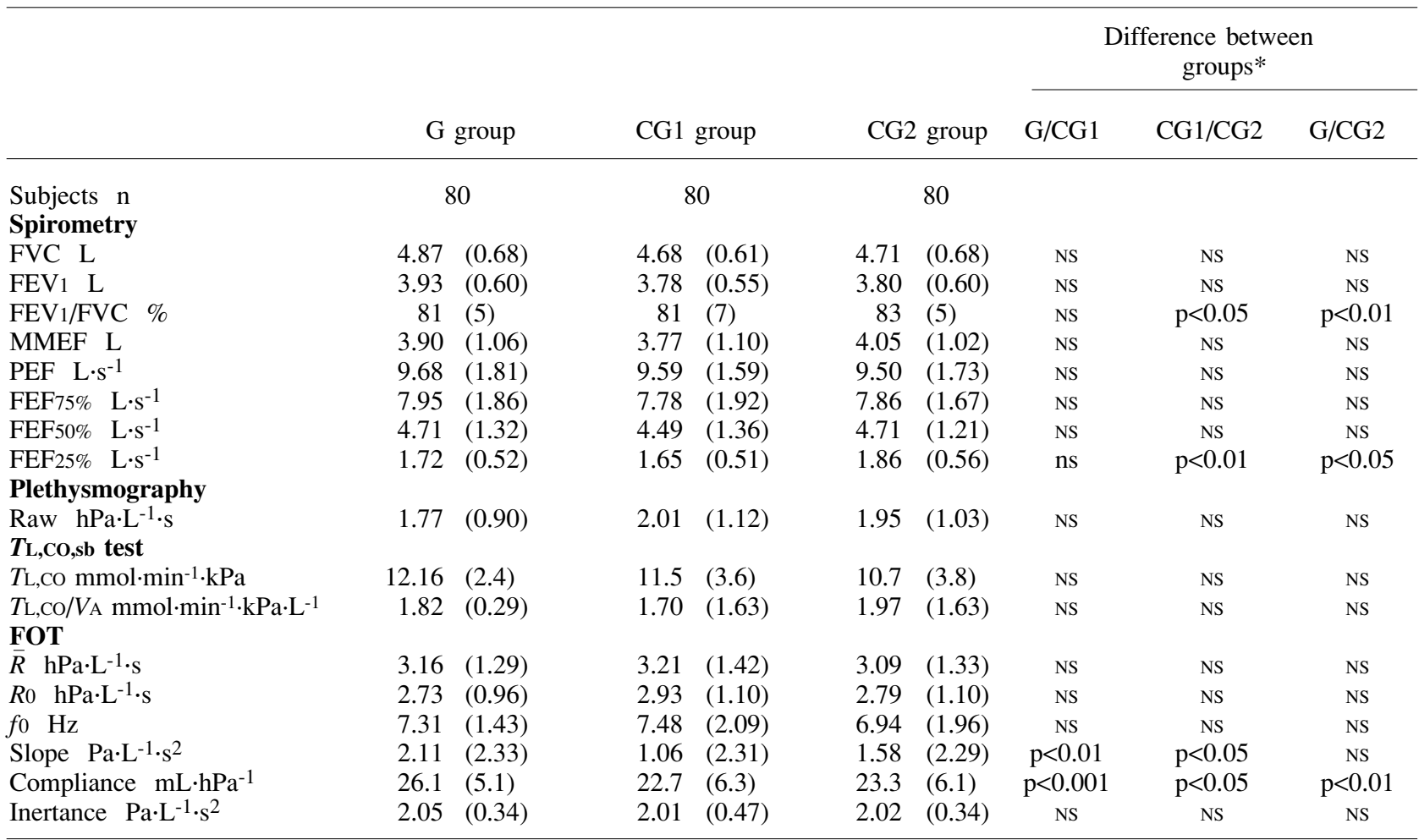

Data are presented as mean, and SD in parenthesis. *: result of covariance analysis (means adjusted on age, weight, height and smoking habits). FVC: forced vital capacity; FEV1: forced expiratory volume in one second; MMEF: maximum mid-expiratory flow; PEF: peak expiratory flow; FEF75\%, FEF50\% and FEF25\%: forced expiratory flow at 75, 50 and 25\% vital capacity; Raw: airway resistance; $T \mathrm{~L}, \mathrm{CO}:$ transfer factor of the lungs for carbon monoxide; sb: single breath; $T \mathrm{~L}, \mathrm{CO} / V_{\mathrm{A}}$ : pulmonary transfer coefficient; $R$ : mean resistance; 
expectoration, dyspnoea and chronic bronchitis were significantly more frequent in the $\mathrm{G}$ group (more than $10 \mathrm{yrs}$ at face-work and with pulmonary roentgenograms classified $0 / 1$ or $1 / 0$ according to ILO classification) than in the two control groups.

No difference was found among the three groups as regards the spirometric, $\mathrm{CO}$ transfer and plethysmographic parameters, with the exception of FEV1/FVC and FEF25\% which were higher in the CG2 group. Regarding the FOT indices, the slope and the compliance were significantly higher in the $\mathrm{G}$ group (table 2).

The frequency of cough equalled $26 \%$ in $\mathrm{G}$ group versus $10 \%$ in the CG1 group $(\mathrm{p}<0.001)$ and $14 \%$ in the CG2 $(\mathrm{p}<0.05)$; expectoration 25 vs $9 \% \quad(\mathrm{p}<0.01)$ and $11 \%(\mathrm{p}<0.01)$, respectively; dyspnoea 22 vs $17 \%$ $(\mathrm{p}<0.01)$ and $10 \%(\mathrm{p}<0.01)$, respectively; and chronic bronchitis 22 vs $9 \%(\mathrm{p}<0.01)$ and $11 \%(\mathrm{p}<0.05)$, respectively.

$\bar{R}, R 0$ and $\mathrm{S}$ were higher in subjects with one or more respiratory symptoms compared with the asymptomatic miners in the $\mathrm{G}$ and the CG1 groups. However, the only significantly different parameters were $S$ for all symptoms in the G group, and $\bar{R}$ and the $R 0$ for dyspnoea in the CG1 group. In the CG2 group no significant difference was noted for any symptom.

The following significant $(\mathrm{p}<0.001)$ correlations were found between FOT and spirometric and plethysmographic indices: $\bar{R}$ mean $v s$ FVC ( $\mathrm{r}=-0.43)$, FEV1 $(\mathrm{r}=-0.60)$, MMEF ( $\mathrm{r}=-0.58)$, PEF ( $\mathrm{r}=-0.58)$, FEF50\% ( $\mathrm{r}=-0.62)$, FEF25\% ( $\mathrm{r}=-0.51)$, and Raw ( $\mathrm{r}=0.58)$. Similar correlations were observed for $R 0$. The correlations were weaker, though still significant $(\mathrm{p}<0.001)$, for the slope $(\mathrm{S})$ with FVC ( $\mathrm{r}=-0.21)$, FEV1 $(\mathrm{r}=-0.38)$, MMEF $(\mathrm{r}=-0.46)$, PEF ( $\mathrm{r}=-0.43)$, FEF50\% ( $\mathrm{r}=-0.50), \mathrm{FEF} 25 \%(\mathrm{r}=-0.38)$, and Raw (r=0.38).

The comparison of the FOT indices in subjects with FEV $1>90 \%$ pred and with FEV $1 \leq 90 \%$ pred is given in table 3. $\bar{R}$ and $R 0$ were the most different indices among the three groups. For the "obstructive" pattern (table 4), both $\bar{R}$ and $\mathrm{S}$ were significantly higher in the $\mathrm{G}$ group, but only the slope in group CG1.

ROC curves for $\bar{R}, R 0$, inertance and compliance with regard to a decreased FEV1 ( $\leq 90 \%$ pred) are presented in figure 2. The highest value of the likelihood ratio defined by (sensitivity/(1 -specificity)) was obtained for $\bar{R}$ $=5 \mathrm{hPa} \cdot \mathrm{L}^{-1} \cdot \mathrm{s}$ (sensitivity $=14.3 \% ;$ specificity $=96 \% ; 91 \%$ well-classified) and for $R 0=4 \mathrm{hPa} \cdot \mathrm{L}^{-1} \cdot \mathrm{s}$ (sensitivity $=36 \%$; specificity $=94 \%$; $91 \%$ well-classified). For the "obstructive" pattern, the likelihood ratio was the highest for $\bar{R}=5$ $\mathrm{hPa} \cdot \mathrm{L}^{-1} \cdot \mathrm{s}$ (sensitivity $=11 \%$; specificity $=96 \% ; 86 \%$ wellclassified) and for $R 0=3.7 \mathrm{hPa} \cdot \mathrm{L}^{-1} \cdot \mathrm{s}$ (sensitivity $=35 \%$; specificity $=94 \% ; 87 \%$ well-classified) (fig. 3).

Table 3. - Forced oscillation technique (FOT) indices in subjects with $\mathrm{FEV}_{1}>90 \%$ or $\mathrm{FEV}_{1} \leq \mathbf{9 0} \%$ predicted

\begin{tabular}{|c|c|c|c|c|c|c|c|c|c|c|}
\hline \multirow{2}{*}{ G group } & \multirow[t]{2}{*}{$\begin{array}{c}\text { Subjects } \\
\mathrm{n}\end{array}$} & \multirow{2}{*}{\multicolumn{2}{|c|}{$\bar{R}$}} & $R 0$ & \multicolumn{2}{|c|}{$f_{0}$} & \multicolumn{2}{|c|}{ Slope } & Compliance & Inertance \\
\hline & & & & & & & & & & \\
\hline $\mathrm{FEV}_{1}>90 \%$ pred & 67 & 2.93 & $(1.01)$ & $2.53 \quad(0.68)$ & 7.14 & $(1.19)$ & 1.90 & $(2.27)$ & $26.6 \quad(5.2)$ & $2.06(0.31)$ \\
\hline $\begin{array}{l}\text { FEV } 1 \leq 90 \% \text { pred } \\
\text { CG1 group }\end{array}$ & 12 & $4.46^{\#}$ & ${ }^{4}(1.85)$ & $3.84^{\#}(1.44)$ & 8.25 & $(2.22)$ & $3.28^{\S}$ & $(2.38)$ & $23.4 *(4.2)$ & $2.01 \quad(0.49)$ \\
\hline $\mathrm{FEV}_{1}>90 \%$ pred & 68 & 2.96 & $(1.19)$ & $2.71 \quad(0.93)$ & 7.30 & $(2.11)$ & 0.73 & $(1.82)$ & $23.1 \quad(6.2)$ & $2.02(0.38)$ \\
\hline $\begin{array}{l}\text { FEV } 1 \leq 90 \% \text { pred } \\
\text { CG2 group }\end{array}$ & 10 & $4.95^{\dagger}$ & $(1.68)$ & $4.34^{\dagger}(1.13)$ & $8.73^{*}$ & $(1.41)$ & $3.29 \S$ & $(3.84)$ & $20.4 \quad(6.9)$ & $1.99(0.88)$ \\
\hline $\mathrm{FEV}_{1}>90 \%$ pred & 67 & 2.92 & $(1.19)$ & $2.63 \quad(1.00)$ & 6.60 & $(1.79)$ & 1.58 & $(2.05)$ & $23.7 \quad(6.1)$ & $2.03(0.35)$ \\
\hline FEV $1 \leq 90 \%$ pred & 12 & $4.01^{\#}$ & ${ }^{*}(1.71)$ & $3.71^{\#}(1.24)$ & $8.81^{\dagger}$ & $(1.89)$ & 1.61 & $(3.49)$ & $20.7 \quad(5.7)$ & $1.97(0.29)$ \\
\hline
\end{tabular}

Data are presented as mean, and SD in parenthesis. For abbreviations and units see legends to tables 1 and 2 . $\$: \mathrm{p}<0.10 ; *$ : $\mathrm{p} \leq 0.05$; \#: $\mathrm{p} \leq 0.01 ;{ }^{\dagger}: \mathrm{p} \leq 0.001$ for the comparison FEV $>90$ vs FEV $<90 \%$ pred.

Table 4. - Forced oscillation technique (FOT) indices in subjects with or without an "obstructive" pattern of ventilatory function

\begin{tabular}{|c|c|c|c|c|c|c|c|c|c|c|c|c|}
\hline \multirow{2}{*}{ G group } & \multirow[t]{2}{*}{$\begin{array}{c}\text { Subjects } \\
\mathrm{n}\end{array}$} & \multicolumn{2}{|c|}{$\bar{R}$} & \multicolumn{2}{|c|}{$R 0$} & \multicolumn{2}{|c|}{$f_{0}$} & \multicolumn{2}{|c|}{ Slope } & \multicolumn{2}{|c|}{ Compliance } & Inertance \\
\hline & & & & & & & & & & & & \\
\hline Syndrome free & 55 & 2.82 & $(0.83)$ & 2.49 & $(0.60)$ & 7.26 & $(1.18)$ & 1.49 & $(1.71)$ & 26.4 & (5.09) & $2.01 \quad(0.27)$ \\
\hline "Obstructive" pattern & 16 & $3.79 *$ & $=(1.61)$ & $3.11^{\S}$ & $(1.21)$ & 6.88 & $(1.35)$ & $3.70^{\#}$ & $(3.12)$ & 26.8 & $(5.10)$ & $2.21 \quad(0.42)$ \\
\hline CG1 group & & & & & & & & & & & & \\
\hline Syndrome free & 58 & 2.91 & $(1.17)$ & 2.72 & $(0.92)$ & 7.26 & $(2.16)$ & 0.53 & $(1.65)$ & 22.9 & $(6.16)$ & $1.98 \quad(0.37)$ \\
\hline "Obstructive" pattern & 13 & 3.82 & $(1.73)$ & 3.12 & $(1.33)$ & 7.77 & $(1.79)$ & $2.90 *$ & $(3.12)$ & 22.7 & $(7.67)$ & $2.28(0.81)$ \\
\hline CG2 group & & & & & & & & & & & & \\
\hline Syndrome free & 63 & 2.85 & $(1.06)$ & 2.55 & $(0.86)$ & 6.58 & $(1.75)$ & 1.58 & (2.07) & 23.9 & $(6.17)$ & $2.04(0.36)$ \\
\hline "Obstructive" pattern & 8 & $4.11^{\S}$ & $(1.75)$ & $3.71 \S$ & $(1.51)$ & $7.79 \S$ & (1.97) & 2.16 & (1.99) & 20.7 & $(4.55)$ & $2.07 \quad(0.28)$ \\
\hline
\end{tabular}

Data are presented as mean, and SD in parenthesis. For abbreviations see legends to tables 1 and 2 . $\S: p<0.10 ; *: p \leq 0.05$; *: $p \leq 0.01$ for the comparison syndrome free $v s$ obstructive pattern. 


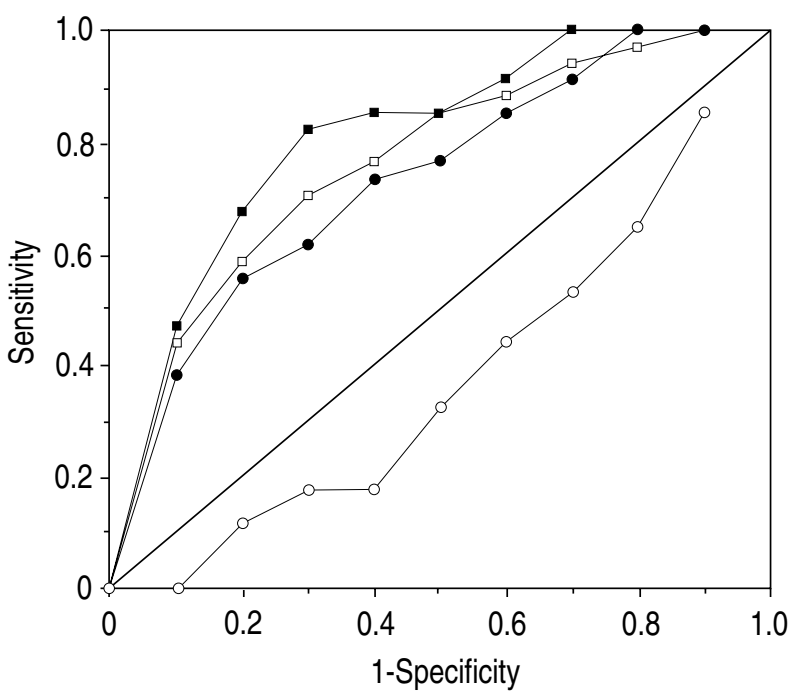

Fig. 2. - Sensitivity and specificity of forced oscillation technique (FOT) parameters with respect to forced expiratory volume in one second $\left(\mathrm{FEV}_{1}\right) \leq 90 \%$ predicted. $-\square-$ : mean resistance $(\bar{R})$; $\longrightarrow$ : resistance at zero frequency $(R 0)$; $\longrightarrow$ : resonant frequency $(f 0)$; —- : compliance.

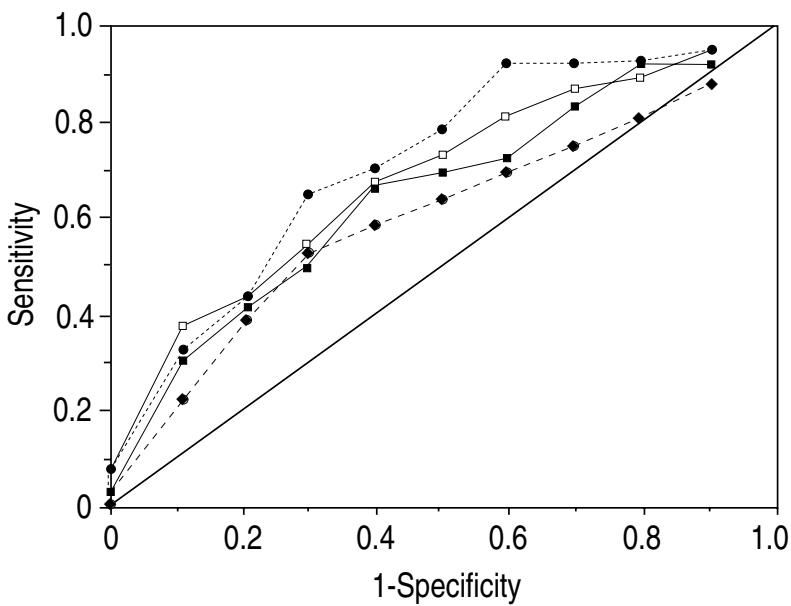

Fig. 3. - Sensitivity and specificity of forced oscillation technique (FOT) parameters with respect to "obstructive" pattern of ventilatory function. $-\square-$ : mean resistance $(\bar{R})$; $\square-$ : resistance at zero frequency $(R 0) ; \cdots \cdots \cdots \cdots . .$. : slope; $--\bullet--$ : inertance.

\section{Discussion}

In this study, the FOT, spirometry, carbon monoxide single-breath test and plethysmography were used to assess the usefulness of FOT in respiratory epidemio$\log$.

In a recent study [21], a comparison was made between two FOT devices, one with a head canopy and the other without. Similar results were observed with both devices. As regards epidemiology, we consider that a device having a head canopy, which avoids holding the cheeks, is more comfortable and easier to use.

The subjects of $\mathrm{G}$ group could be considered, on the basis of the selection criteria, as representative of the population "suspected" of pneumoconiosis. The subjects of both control groups might not, theoretically, be considered as representative of the population of miners of the same status, though the bias due to the matching criteria would in fact be small. Indeed, the smoking habit distributions of the three groups of miners should be similar. However, we preferred to present the results for the three groups separately, with the exception of the calculations of the sensitivity and specificity of various FOT indices for a decreased FEV1 $(\leq 90 \%$ pred) and for the presence of an "obstructive" pattern (given in figures 2 and 3, respectively) due to the small number of subjects with such abnormalities.

The dust concentrations measured in 1989 indicated significant differences between the coal-face and other underground work sites. In the past, these concentrations have undoubtedly been greater. An individual evaluation of exposure to dust, based on detailed job-exposure matrices, is currently in progress. This assessment will take into account changes in methods for measuring dust exposure, as well as migration of miners from one work site to another. Although these figures are not yet available, it can, nevertheless, be considered that miners at the coal-face were significantly more exposed than other underground workers.

In the present study, the subjects were grouped according to the changes identified on their chest radiographs. We do not know why some miners develop roentgenological changes and others do not when exposed to an apparently similar dust content. A follow-up study is planned and the assessment of individual exposure is in progress; and it is hoped that these data will help to improve understanding of the natural history of pneumoconiosis in coal miners.

No differences were found among the three groups using parameters of spirometry, carbon monoxide test and airway resistance measured by plethysmography. Among the FOT indices, the slope was found to be significantly higher in the $\mathrm{G}$ group. This index characterizes the average frequency dependence of the resistance over the entire frequency range, and is believed to be an early sign of functional disturbances. The interpretation of the frequency dependent behaviour of the respiratory system has been clearly discussed by WOUTERs [22], and higher values of slope have also been noted both by JORNA et al. [23] and MURPHY et al. [24], in subjects with pneumoconiosis. In a previous study, the slope was found to be the only functional index which showed a significant difference between children exposed to urban air pollution and those of the same age and from the same area not having been exposed [7]. As suggested by STANeScu et al. [25], it could represent an early manifestation of peripheral airway obstruction. Similar results were also reported by KJELDGAARD et al. [26], and PESLIN et al. [27], in asymptomatic smokers as compared with nonsmokers. These authors, as well as INGRAM and O'CAIN [6], suggested a similarity between slope and frequency-dependence of lung compliance to distinguish asymptomatic smokers from nonsmokers. This measurement requires an oesophageal balloon to obtain the thoracic pressure variations, and is thus relatively invasive, whereas the FOT is both noninvasive and requires no special respiratory manoeuvres. 
Slope, $\bar{R}$, and $R 0$ were significantly higher in workers with cough, dyspnoea or bronchitis compared with asymptomatic subjects in the $\mathrm{G}$ and the CG1 groups, although the difference was significant only for slope and in the $\mathrm{G}$ group, possibly due to the small number of subjects. These results were similar to those reported by VAN Noord et al. [28], Clement et al. [29], Grimby et al. [30] Forster et al. [31], and Wouters et al. [32], in patients with chronic obstructive pulmonary disease (COPD).

Sensitivity and specificity of $R 0$ and $\bar{R}$ with regard to a decreased FEV1 and to the presence of a mild obstructive pattern of lung function has reinforced the idea that FOT may be useful in the diagnosis of COPD.

In the CG2 group, no significant difference was observed between the subjects with a respiratory symptom and those asymptomatic for any FOT index. This could be explained by the fact that the miners of this group had few symptoms.

$R 0$ and $\bar{R}$ were the indices most clearly linked to $R$ aw and to all indices of mean and instantaneous flows. The highest relationships were noted in the G group. Similar results were observed in one of our previous studies and by Wouters [8], KJeldgaArd et al. [26], and VAN NoORD et al. [28].

These results and the clear difference in FOT indices when either a mild obstruction (defined by FEV $1 \leq 90 \%$ pred) or an "obstructive" pattern (defined by certain spirometric characteristics) was present, in addition to the change of slope that may be an early index of a functional respiratory disturbance would tend to suggest that FOT may be a useful tool in respiratory epidemiology. This is strengthened by the fact that the FOT is both easy to use and has a high degree of acceptability. This further supports the usefulness of FOT in epidemiology pointed out by others [23, 32-36], as regards the measurement of bronchial changes to test hyperactivity [3236].

Acknowledgements: The authors would like to thank Y. Hauquiert and A. Berthelin for the preparation of the manuscript, M. Marchand for his technical help, and the technical staff of the Medical department of Houillères du Bassin de Lorraine for their help in subject selection.

\section{References}

1. Hayes DA, Pimmel L, Fulton JM, Bromberg PA. Detection of respiratory mechanical dysfunction by forced random noise impedance parameters. Am Rev Respir Dis 1979; 120: 1095-1100.

2. Landsër FJ, Clement J, Van de Woestijne KP. Normal values of total respiratory resistance and reactance determined by forced oscillations: influence of smoking. Chest 1982; 81: 586-591.

3. Nolte D, Berger D, Forster E. Theoretical and clinical aspects of impedance measurements of the respiratory system. In: Matthys $\mathrm{H}$, ed. Progress in Respiration research. Biomedical Engineering and Data Processing in Pneumology. Basel, Karger, 1979; 11: 172-178.

4. Peslin R, Galina C, Duvivier C. Respiratory transfer impedances with pressure input at the mouth and the chest. J Appl Physiol 1986; 61: 81-86.
5. Peslin R, Fredberg J. In: Oscillation mechanics of the respiratory system. Handbook of Physiology. The Respiratory System. III. Chap. 11. 1986; pp. 145-177.

6. Ingram RH, O'Cain CF. Frequency dependence of compliance in apparently healthy smokers versus nonsmokers. Bull Eur Physiopathol Respir 1971; 7: 197-200.

7. Peslin R, Galina C, Teculescu D, Pham QT. Respiratory input and transfer impedances in children 9-13 years old. Bull Eur Physiopathol Respir 1987; 23: 107-112.

8. Wouters EFM, Verschoof AC, Polko AK, Visser BF. Impedance measurements of the respiratory system before and after salbutamol in COLD patients. Respir Med 1989; 83: 309-313.

9. Peslin R, Pham QT, Teculescu D, Galina C, Duvivier C. Comparative value of respiratory input and transfer impedances in field studies. Bull Eur Physiopathol Respir 1987; 23: 37-42.

10. Grimby G. Measurement of respiratory resistance with forced oscillations. Scand J Clin Lab Invest 1969; 24 (Suppl. 10): 37-39.

11. Dubois AB, Brody AW, Lewis DH, Burgess BF. Oscillation mechanics of lung and chest in man. J Appl Physiol 1956; 8: 546-549.

12. International Labour Office (ILO). Guidelines for the use of ILO international classification of radiographs of pneumoconiosis. Occupational safety and health series No. 22. Geneva, ILO, 1980.

13. Caillier I, Bruant A, Mahieu B, et al. Constitution d'un échantillon de sujets à l'aide d'une étude de concordance inter-observateurs. Application à des mineurs suspects de pneumoconioses. Arch Mal Prof 1991; 52: 541-548.

14. Peslin R, Bohadana A, Hannhart B, Jardin P. Comparison of various methods for reading maximal expiratory flow-volume curves. Am Rev Respir Dis 1979; 119: 123-130.

15. Quanjer $\mathrm{PhH}$. Standardised lung function testing. European Community for coal and steel. Bull Eur Physiopathol Respir 1983; 19 (Suppl. 5): 45-51.

16. Duvivier C, Peslin R, Wendling G, et al. Mesure de l'impédance thoraco-pulmonaire par oscillations forcées, présentation d'un appareil. Innov Technol Biol Med 1990; 11: 381-399.

17. Rotger M, Peslin R, Navajas D, Galina C, Duvivier C. Density dependence of respiratory input impedance reevaluated with a head generator minimising upper airway shunt. Eur Respir J 1988; 1: 439-444.

18. Armitage P, Berry G. In: Statistical Methods in Medical Research. Oxford, Blackwell Scientific Publications, 1987.

19. Metz CE. Basic principles of ROC analysis. Semin Nucl Med 1978; Vol. VIII (4): 283-299.

20. SAS Institute. SAS/Stat guide for personal computers. Cary, NC, SAS Institute Inc., 1992.

21. Iwatsubo $\mathrm{Y}$, Lorino $\mathrm{H}$, Hubert $\mathrm{C}$, et al. Measurement of respiratory impedance by forced oscillation: comparison of the standard and head generator methods. Eur Respir J 1994; 7: 901-906.

22. Wouters EFM. Total respiratory impedance measurement by forced oscillation: a noninvasive method to assess bronchial response in occupational medicine. Exp Lung Res 1990; 16: 25-40.

23. Jorna THJM, Borm PJA, Lanaerts L, Schins RPF, Derhaag T, Wouters EFM. Airway obstruction in retired coal workers is present at early stages of pneumoconiosis. Am Rev Respir Dis 1993; 147 (4): A902.

24. Murphy DM, Metzger LF, Silage A, Hollmann LM. Frequency dependent resistance in simple coal workers' 
pneumoconiosis. Am Rev Respir Dis 1981; 123 (Suppl.): 143.

25. Stanescu D, Fesler DC, Veriter C, Frans A, Brasseur L. A modified measurement of respiratory resistance by forced oscillation during normal breathing. J Appl Physiol 1975; 39: 305-311.

26. Kjeldgaard JM, Hyde RW, Speers DM, Reichert WW. Frequency dependence of total respiratory resistance in early airway disease. Am Rev Respir Dis 1976; 114: 501-508.

27. Peslin R, Hannhart B, Pino J. Impédance mécanique thoraco-pulmonaire chez les fumeurs et nonfumeurs. Bull Eur Physiopathol Respir 1981; 17: 93-105.

28. Van Noord JA, Clement J, Van De Woestijne KP, Demedts M. Total respiratory resistance and reactance in patients with asthma, chronic bronchitis and emphysema. Am Rev Respir Dis 1991; 143: 922-927.

29. Clement J, Landser FJ, Van De Woestijne KP. Total resistance and reactance in patients with respiratory complaints with and without airways obstruction. Chest 1983; 83: 215-220.

30. Grimby G, Takishima T, Graham W, Macklem P, Mead $\mathrm{J}$. Frequency dependence of flow resistance in patients with obstructive lung disease. Clin Invest Med 1968; 47: $1455-1465$
31. Forster E, Berger D, Nolte D. Vergleichmessungen des atemwiderstandes mit der oszillations methode und mit der body plethysmographie. Verh Dtsch Ges Inn Med 1978; 84: 956-965.

32. Wouters EFM, Mostert R, Polko AH, Visser BF. Forced expiratory flow and oscillometric impedance measurement in evaluating airway obstruction. Respir Med 1990; 84: 205-209.

33. Wouters EFM. Total respiratory impedance measurement by forced oscillations: a noninvasive method to assess bronchial response in occupational medicine. Exp Lung Res 1990; 16: 25-40.

34. Fischer J, Matthys H, Rühle H, Klein G. Oscillatory resistance and forced expiratory measurements for screening lung disorders. In: Matthys $\mathrm{H}$, ed. Progress in Respiration Research. Biomedical Engineering and Data Processing in Pneumology. Basel, Karger, 1979; 11: pp. 202-214.

35. Brochard L, Pelle G, De Palmas J, et al. Density and frequency dependence of resistance in early airway obstruction. Am Rev Respir Dis 1987; 135: 579-584.

36. Jorna THJM, Borm PJA, Maestrelli P, Fabbri LM, Wouters EFM. Localisation of airway obstruction by impedance measurements in isocyanate-induced asthmatic reactions. Am Rev Respir Dis 1993; 147 (4): A115. 